\title{
MONTSENY ENTRE RUINAS: IMPRESIONES ARQUEOLÓGICAS DE UNA ANARQUISTA
}

\author{
MONTSENY AMONG RUINS: \\ ARCHAEOLOGICAL IMPRESSIONS OF AN ANARCHIST
}

\author{
Tomás Aguilera DuráN* \\ Grupo de Investigación Occidens
}

\begin{abstract}
RESUMEN. Este artículo se aproxima al desconocido campo de la recepción de la Antigüedad en el pensamiento anarquista mediante el análisis de un texto específico: un artículo de 1926 sobre la ciudad de Ampurias escrito por Federica Montseny en La Revista Blanca, una autora y una publicación emblemáticas del periodo de auge de la ideología libertaria en España. Se comentan y contextualizan varias facetas del texto: el legado literario que incidió sobre su evocación poética de las ruinas, la proyección de la información histórica y arqueológica derivada de las excavaciones coetáneas, su idealización filohelenista vinculada al refuerzo identitario catalanista y el mensaje anticristiano que transmite al confrontar las distintas etapas del enclave. Se sondean así algunos temas, conexiones y particularidades en la compleja relación entre anarquismo y mundo antiguo.
\end{abstract}

PALABRAS CLAVE: anarquismo, filohelenismo, Ampurias, Federica Montseny, La Revista Blanca.

ABSTRACT. This work, through a particular text by Federica Montseny, tackles with the unknown issue of the reception of Antiquity by the anarchist movement. Federica Montseny, a significant Spanish author, wrote an article in 1926, the heyday of libertarian ideology in Spain, about the city of Emporion which she published in the compelling magazine La Revista Blanca. The paper disserts on and contextualises the diverse dimensions of the text by Montseny: the literary legacy projected on the poetic evocation of the ruins, the scope of the new historical and archaeological data provided by the coetaneous excavations, her philhellenic idealization derived from the identity reinforcement occurring at the time in Catalonia, the spreading of an antichristian message resulted from the confrontation by Montseny of the different periods of the archaeological site. Thus, this paper explores several of the issues, connections and features of the complex relationship between Anarchism and Ancient World.

KEYWORDS: anarchism, philhellenism, Emporion, Federica Montseny, La Revista Blanca.

\footnotetext{
* Correspondencia a / Correspondence to: Tomás Aguilera Durán. C/ Muñoz Torrero 3, 1. ${ }^{\circ}$ A (28004, Madrid) - tomas.aguileraduran@gmail.com http://orcid.org/0000-0001-6913-3424.

Cómo citar / How to cite: Aguilera Durán, T. (2019), "Montseny entre ruinas: impresiones arqueológicas de una anarquista», Veleia, 36, 111-124. (https://doi.org/10.1387/veleia.20731).
}

Recibido: 2 abril 2019; aceptado: 3 junio 2019.

ISSN 0213-2095 - elSSN 2444-3565 / (C 2019 UPV/EHU 
«De Ampurias, de las ruinas de sus tres civilizaciones, puede también sacarse una consecuencia, encontrarse en ella un símbolo.» (Montseny 1926, 110)

Este artículo propone aproximarse a un tema aparentemente poco explorado: la recepción de la Antigüedad en el pensamiento anarquista en España. No creo necesario argumentar la importancia de este movimiento en la historia política española (Termes Ardèvol 2011; Vadillo Muñoz 2019), como tampoco parece preciso resaltar la complejidad de sus ramificaciones intelectuales y culturales (Hofmann et al. 1995; Morales Muñoz 2002; Lida \& Yankelevich 2012); ahora bien, aparentemente, nunca se ha planteado un análisis de las percepciones, recursos y representaciones del mundo antiguo en su discurso ${ }^{1}$.

La advertencia anterior tiene su sentido, entre otras cosas, para justificar el tipo de trabajo que aquí se presenta: el comentario de un texto muy breve y concreto, con el que no se pretende establecer ningún modelo interpretativo general ni exhaustivo, sino sondear algunos temas, conexiones y líneas de análisis con los que abordar esa peculiar relación. En todo caso, tomo como punto de partida una hipótesis algo obvia e intuitiva: si bien la recepción anarquista de la Antigüedad comparte tendencias con otras corrientes progresistas - en especial con otros movimientos socialistas-, como es esperable, también se observan divergencias derivadas de sus especificidades ideológicas. Me refiero a ciertos condicionantes particularmente marcados, como el antitradicionalismo, el antiautoritarismo, el hipercriticismo o el individualismo, este último especialmente definitorio de ciertas expresiones más intelectualistas, como en el caso que nos ocupa. Tales factores propician planteamientos muy diversos ante cuestiones similares, incluso entre pensadores de posturas y ambientes cercanos, además de una cierta permeabilidad ecléctica más difícil de encontrar en corrientes más dogmáticas y estructuradas. Así, la ausencia de antecedentes, por un lado, y la aparente heterogeneidad del fenómeno, por otro, se alían en favor de este tipo de aproximación microhistórica a la fuente y el autor en sus circunstancias específicas.

En cualquier caso, la elección de este texto tiene una cierta justificación: la relevancia de la autora, del medio y de la fecha de publicación, en un periodo de auge del movimiento. Federica Montseny (1905-1994) es una figura imprescindible del anarquismo en España en el siglo xx, como cabeza visible de la CNT y la FAI en momentos decisivos como la Revolución de 1934 y la Guerra Civil, como ministra en el gobierno de Francisco Largo Caballero y como referente de la izquierda desde el exilio. Nos atañe aquí, no obstante, su etapa de juventud (Montseny 1987; Lozano 2004, 21-106; Alcalde 1983, 26-46; Rodrigo 2014, 17-74). Nacida de la unión civil de Teresa Mañé, pedagoga y precursora de la educación laica, y Joan Montseny (o Federico Urales), maestro, editor y sindicalista clave en la consolidación del anarquismo español, Federica se formó con sus padres, al margen del sistema educativo, en un entorno familiar, social e intelectual atípico, un verdadero "laboratorio de ideas» de inspiración libertaria con un alto nivel cultural y un fuerte compromiso político (Marín i Silvestre \& Palomar i Abadía 2010).

Parte esencial de ese caldo de cultivo fue la labor editorial dirigida por sus padres. Por encima de todo, ellos fundaron y dirigieron La Revista Blanca (1898-1905, 1923-1936). De entre la multitud de publicaciones obreristas del momento, usualmente apegadas a las noticias de actualidad y las llamadas a la acción, esta se distingue por ser un ejemplo casi único en Espańa de revista culta, al estilo de las publicaciones burguesas, pero de ideología revolucionaria. Con cuarenta páginas y periodicidad quincenal, se hacía eco de las últimas tendencias en ciencias, huma-

1 Sí se ha hecho con algunos referentes universales, como Pierre-Joseph Proudhon (García Jurado 2014), además de algunas notas generalistas en medios militantes (García Morales 2012; Ferri 2017). 
nidades, arte y literatura, con la colaboración de intelectuales de primer nivel, no anarquistas, pero simpatizantes, como Miguel de Unamuno o Giner de los Ríos. No por eso dejaba de ser una publicación militante y abiertamente libertaria, surgida al calor de los procesos de Montjuic y empleada siempre como medio de recaudación en beneficio de presos anarquistas. A esa combinación particular se suma su notable difusión, con tiradas de 8.000-12.000 ejemplares, además de constituir el germen de otras iniciativas editoriales, como el popular diario Tierra y Libertad, que empezó como un suplemento suyo, o las colecciones de novelas sociales, La Novela Ideal y La Novela Libre. Todo ello la convierte en una publicación fundamental para entender el desarrollo intelectual y la difusión de las ideas anarquistas en España en el primer tercio del siglo xx (Madrid Santos 1989; Litvak 1995; Valle-Inclán 2008). En definitiva, por su proyección y por el desacostumbrado espacio que brindaba a la reflexión historiográfica, filosófica y literaria, si hay una fuente apropiada para estudiar la recepción de la Antigüedad en el anarquismo español, esa es La Revista Blanca ${ }^{2}$.

Y dentro de ese proyecto editorial, Federica ocupó un papel importante; de hecho, ella fue impulsora junto a sus padres de la refundación de la revista en su segunda época y, aparte de trabajar en la edición, ya publicaba intensamente desde los quince años, firmando innumerables artículos y una cincuentena de novelas romántico-sociales. Ciertamente, en su prolífica vida de escritora y ensayista, los temas de arqueología o cultura clásica fueron prácticamente inexistentes, lo que hace aún más significativa la rareza que nos ocupa.

El 15 de julio de 1926, Montseny publicó «La ciudad muerta. Ruinas de Ampurias». Tenía 21 años y estaba en un momento clave de afirmación personal y militante, consolidándose como escritora y ya como afiliada a CNT desde 1923. El artículo es una breve crónica de una visita al yacimiento de Ampurias, dividido en cuatro partes en las que alterna la descripción del lugar con recreaciones literarias y reflexiones ideológicas. Según cuenta, fue guiada por unos amigos de L'Escala y, aunque no dice cuándo fue exactamente, da la impresión de que había sido muy reciente. Encaja en su cronología vital; desde 1918 la familia se había asentado en Barcelona después de muchos vaivenes y, como ella recordaría sesenta años después, la estabilidad que conllevó aquella nueva etapa les dio la oportunidad de hacer visitas por toda Catalunya. Entre esos lugares, aquella ciudad antigua se había instalado especialmente en su memoria: «Las visitas a las ruinas de Ampurias, que poblaban de imágenes mi pensamiento fantasioso» (Montseny 1987, 45). En esta retrospectiva habla en plural, pero en el artículo recalca que fue una única visita, muy fugaz y, además, entorpecida por una lluvia intermitente; al parecer, aquella fue su primera experiencia allí y, aunque muy probablemente hubo otras después ${ }^{3}$, aquella primera impresión le causó un profundo impacto.

2 Son muchas las colaboraciones que remiten a la Antigüedad. Un ejemplo destacado por su periodicidad es la sección "Divulgaciones Históricas», dedicada exclusivamente a semblanzas de escritores griegos y latinos, aunque en un tono muy neutro y didáctico, firmada por M. Soriano de Numancia.

3 Una probable visita posterior pudo haberse producido en el ańo 1928 acompañando al ale- mán Max Nettlau, historiador del anarquismo. Ese año visitó España invitado por la familia MañéMontseny, con la que hizo varias excursiones (Lozano 2004, 96). Poco después, Nettlau (1929, 181182), en un artículo en La Revista Blanca, mencionó precisamente a Numancia y Ampurias como ejemplos de lo que la arqueología moderna aportaba al estudio del pasado. 


\section{LA RUINA Y SUS FANTASMAS}

«Dejaron en mi mente la impresión pesada y confusa del pasado misterioso y lejano, la sugestión poderosa y vaga de la vida muerta que palpitó en ellas.» (Montseny 1926, 108)

El artículo es puro romanticismo, lo que encaja con el hecho de que se tratase de un trabajo de juventud, aunque realmente no desentona con el estilo literario de Montseny en general. Especialmente la primera parte (Montseny 1926, 108-109) está destinada a situar al lector en un escenario cargado de fuerza evocadora y sugestión poética, a presentarle un marco de fondo protagonizado por una naturaleza de presencia imponente: el mar es omnipresente, su "perenne rumor» acariciando los muros y su «terrible majestad» durante las tormentas, todo ello bajo un cielo sobrecogedor, de «luz prodigiosa».

En ese escenario atemporal se sitúan unas ruinas perfiladas aún en abstracto, sin una consistencia concreta, representando, justamente, el papel contrario al de la naturaleza: el paso del tiempo. En este punto remite en su máxima expresión al arraigado tópico literario del ubi sunt, de la ruina como símbolo y como recordatorio de la existencia efímera del ser humano (Ferri Coll 1995). En el texto son constantes las referencias a la posibilidad de conectar con el pasado al pisar sus calles en el mismo lugar donde los antiguos habían pisado, donde permanecían sus huellas invisibles, tocar las columnas entre las que habían vivido o encontrarse con la impronta de su vida cotidiana, como las roderas dejadas por sus carros en la entrada de la ciudad (romana) o los fragmentos de asas de ánfora que podían encontrarse en el suelo. De esta manera, la más pura materialidad de la ciudad y sus objetos, por insignificantes que fuesen, permitía establecer una cierta conexión emocional entre el visitante y los seres del pasado. Aun tratándose de conceptos recurrentes, este énfasis en la capacidad de la ruina para transmitir imágenes y sensaciones, su calidad como espacio de memoria, es llevado un poco más allá por Montseny mediante una fantasía más concreta que propone al inicio y reaparece a lo largo de todo el artículo: la posibilidad de viajar en el tiempo pasando una noche entre las ruinas, de manera que, de una forma onírica, fuese transportada al pasado para encontrarse con los fantasmas de la ciudad antigua.

No resulta fácil adivinar sus posibles referentes literarios cuando se trata, además, de tópicos tan recurrentes. Ella fue una lectora voraz, que creció en un hogar donde los libros copaban hasta los rincones más insospechados, como ella misma contó reconociendo que sus lecturas juveniles fueron tan abundantes como diversas en cuanto a género, calidad y tradición (Montseny 1987, 17-25). En los listados que recogió a modo de muestra no figura ninguna obra que pudiese haber constituido un referente obvio en este tema; no obstante, pueden hacerse algunas consideraciones.

La propia Ampurias ya traía consigo un potente bagaje literario y, más concretamente, se había convertido en todo un emblema del Noucentisme catalán. Concebido como reacción al Modernismo, este movimiento estético apostaba por el clasicismo más puro, en tema y forma (Vallcorba Plana 1994; Cabré et al. 2003; Trullén i Thomàs \& Martinell i Callico 2009). Consecuentemente, la cultura griega adquirió un peso simbólico fundamental, plasmado, por ejemplo, en las traducciones del griego al catalán de Joan Maragall y Lluis Segalà. Lógicamente, esto situó a Ampurias en el centro de la producción creativa, pues se constituyó como un símbolo del apogeo heleno en Catalunya (Cortadella Morral 2009). Volveré luego sobre la dimensión ideológica de este fenómeno; por el momento cabe destacar de ese ambiente obras como Dans les ruines d'Ampurias (1918), un conjunto de 42 sonetos de la poetisa francesa de ascendencia catalana Andrée Bruguiére de Gorgot, que fue publicado con un notable éxito en formato bilingüe (francés y traducción catalana) (Velaz i Sicart 2003). Es bastante plausible que Montseny conociese esta obra y no solo lo sugiere la semejanza de su subtítulo. Es verdad que no hay nada en su artículo sobre los hechos y personajes 
históricos, cartagineses y romanos, que tienen gran presencia en la obra de Gorgot. Por el contrario, sí pueden encontrarse ciertos lugares comunes, aunque muy genéricos, en los sonetos más simbólicos, aquellos que se ocupan del poder evocador del paisaje, la poetización del hecho cotidiano y su capacidad de conectar la Antigüedad con el visitante presente; es el caso de "La cité des morts», cuyo nombre, quizá, sirvió para completar el título del artículo.

Por otro lado, Montseny compara a Ampurias con otras ciudades antiguas que también tenían una consistente entidad literaria. Menciona a Numancia y Sagunto, aunque solo tangencialmente, aludiendo a su final repentino; aparte de las recreaciones de su destrucción, sus ruinas — reales o imaginadas - también habían inspirado múltiples ejercicios poéticos (García Cardiel 2013). También alude a Palmira (aunque, al comparar, le resta encanto por carecer de costa); este ejemplo no es el más habitual y no deja de ser llamativo que el libro de viajes más famoso sobre sus restos, Las ruinas de Palmira de Volney (1791), lo estuviese distribuyendo la editorial familiar de Montseny ${ }^{4}$, aunque sus conexiones no pueden llevarse mucho más allá.

Ahora bien, cuando Montseny juega con esa posibilidad extrema de encontrarse entre las ruinas, de noche, con los espectros del pasado, me da la sensación de que ha leído algo sobre Pompeya, a la que también menciona. En efecto, esa idea de la experiencia sobrenatural, ya fuese empírica o metafórica, era una imagen particularmente potente en el mito pompeyano. Ayudaba su conservación intacta, el hallazgo de sus esqueletos y la creación de los moldes de sus habitantes agonizantes (Moormann 2015); así lo plasmó el sugerente cuadro de Paul de Curzon, de ilustrativo título, Un rêve dans les ruines de Pompeï. Les ombres des anciens habitants reviennent visiter leurs demeures (1866). Más concretamente, ese motivo del viaje onírico en el tiempo de un visitante fue un argumento literario recurrente. Inaugurado por Théophile Gautier en su novela Arria Marcella (1852), Thomas Jensen lo reinventó, con un aire más simbolista, en Gradiva (1902), obteniendo un enorme éxito internacional. Sigmund Freud analizó la novela como ejercicio sobre la exploración del inconsciente (Der Wahn und die Träume in W. Jensens Gradiva, 1907), lo que a su vez inspiró los experimentos surrealistas de Salvador Dalí (Gradiva descubre las ruinas antropomorfas, 1932) y André Masson (Gradiva, 1939). O bien a Montseny se le ocurrió la misma idea que a ellos al contemplar Ampurias, o bien aplicó a su caso aquel tópico pompeyano; contaba, en todo caso, con un rico abanico de recursos para colorear la evocación de sus ruinas.

\section{DE MERCADERES Y DESESCOMBROS}

Aunque ese tipo de evocación poética no deja de reaparecer a lo largo de todo el texto, a partir de la segunda parte comienza a concretarse con un contenido más descriptivo, tocando ciertas cuestiones de tipo arqueológico (Montseny 1926, 109). No es que Montseny tuviese un interés ni un conocimiento especial sobre estos temas (de hecho, no los tenía), pero esta incursión puntual es muy comprensible si tenemos en cuenta su contexto. He mencionado antes la recurrencia de Ampurias en la literatura novecentista, y esa presencia en el imaginario catalán no era algo aislado, sino que estuvo íntimamente ligada al redescubrimiento arqueológico del sitio.

Más allá de alguna intervención puntual, la excavación de Ampurias era una asignatura pendiente que se abordó en 1908 con el impulso de Enric Prat de la Riba, uno de los principales ideólogos del nacionalismo catalán y cofundador de la Lliga Regionalista que lideraría el catalanismo

${ }^{4}$ Aparte de su aparición en los catálogos de La Revista Blanca durante años, véase la nota editorial en la página XIII del suplemento del 15 de septiembre de 1926. 
conservador en esos años. Siendo él entonces presidente de la Diputació de Barcelona, esta excavación se integró en un amplio proyecto de reconstrucción nacionalizadora de las instituciones catalanas. Esto incluyó la fundación del Institut d'Estudis Catalans (1907) y el Servei d'Investigacions Arqueològiques (1915), que funcionaron como vertebradores en la conformación de un marco propio de investigación y difusión humanística al margen de la Administración central y, con ello, en la elaboración de un discurso histórico-cultural independiente destinado a fortalecer las bases culturales y sociales del proyecto político catalanista. Las intervenciones, que se desarrollaron entre 1908 y 1936, fueron dirigidas por el arquitecto Josep Puig i Cadafalch, con el apoyo de Emili Gandía, y, centradas en la fase griega, sacaron a la luz buena parte de la Neápolis, completándose con la instauración del Museum Emporium (1914) y una intensa labor de publicación científica de los resultados, fundamentalmente a través del Anuari del Institut d'Estudis Catalans (Aquilué Abadías 2001; Ripoll i Perelló 2001; Gracia Alonso 2013; 2017). En efecto, tan trascendente como la propia investigación fue el potente aparato propagandístico del que se acompañó; las instituciones y la prensa afín magnificaron inmediatamente cada uno de los hallazgos, de forma que se convirtió en todo un fenómeno turístico, explotado mediante viajes organizados, edición de guías y desarrollo hostelero, una industria donde la ideologización del patrimonio se entremezclaba con intereses económicos (Boix Llonch 2001; Munilla \& Gracia Alonso 2016).

Ese proceso de puesta en valor del enclave tiene cierto eco en algunos de los puntos del artículo de Montseny. Resulta llamativa la referencia que dedica a los expoliadores cuando habla de los «metales preciosos, monedas y objetos hoy de valor incalculable, de los que se han apoderado vorazmente los mercaderes de la arqueología y del arte» (Montseny 1926, 109), una cuestión —la del coleccionismo privado en torno al yacimiento - que era muy real y bien conocida (Vallvé Albiol 2005). Por otro lado, son interesantes las pistas que aporta acerca del estado de las excavaciones: relata el paseo por un campo de maíz sobre una sección de la ciudad aún enterrada (probablemente parte de la ciudad romana) y, lo que es más significativo, hace dos alusiones a la interrupción de las excavaciones. En sus términos, habla de la "paralización del desescombro» y del "paulatino y ahora interrumpido desescombro», que sería visible en algunas calles y murallas. Cabe la posibilidad de que se trate simplemente de una percepción personal sobre la conservación de las ruinas, pero también es plausible que refleje un proceso real de relativo abandono.

En las intervenciones ampuritanas parece decisiva la instauración de la dictadura de Primo de Rivera. Como parte de su política de uniformización centralista, en 1924 el gobernador militar de Barcelona, Carlos de Lossada, destituyó a Puig i Cadafalch de la presidencia de la Mancomunitat de Catalunya (que ocupaba desde la muerte de Prat de la Riba en 1917) y disolvió la institución al año siguiente, paralizándose las iniciativas políticas y culturales que se habían estado desarrollando bajo su amparo. Con Puig i Cadafalch desplazado, Gandía continuó el trabajo de campo en Ampurias, pero, efectivamente, parece que esos años fueron complicados y las excavaciones quedaron estancadas en alguna medida (Ripoll i Perelló 2001, 48-50). Esto transmiten las dos breves notas que constituyen la publicación de los resultados de ese periodo, en contraste con la intensa actividad de los años previos: en el número del Anuari del Institut d'Estudis Catalans correspondiente a 1921-1926, la información sobre las campañas se interrumpe en 1923 (Serra i Ràfols 1931); en el siguiente volumen se mencionan discretamente las circunstancias de esa interrupción:

«L'any 1924 foren encara continuades les excavacions d'Empúries, pero no ha estat possible d'incloure en l'anterior ANUARI la descripció del resultat obtingut per raons conegudes, que no cal esmentar. Per això es reprèn la ressenya en el present desde l'any 1924 fins al moment en què els governants consideraren inútil prosseguir la recerca científica.» (Puig i Cadafalch 1936, 56) 
En efecto, en las fechas en las que Montseny probablemente visitó Ampurias, si bien el yacimiento era célebre y la afluencia turística intensa, las excavaciones no estaban en su mejor momento, una vez que habían perdido el impulso institucional antes propiciado por la Lliga y ahora paralizado por la dictadura. Es más que probable que existiese una consciencia general en Catalunya - presumiblemente negativa - acerca de este entorpecimiento políticamente condicionado de la investigación en el sitio; desde luego, así sería en el entorno local más inmediato, como el de esos amigos de L'Escala que guiaron e informaron a la autora.

Por lo demás, las referencias historiográficas y arqueológicas de Montseny se caracterizan por una cierta imprecisión recurrente. Para empezar, se atreve con cierto cultismo toponímico al contraponer la «Emporiae» griega con la «Ampurias» medieval, aunque lo hace erróneamente, ya que utiliza la forma latina (Emporiae) donde correspondería la griega (Emporion). Por otro lado, aunque se centra en el periodo griego, menciona el origen fenicio, apuntando, curiosamente, que su antiguo nombre era "Alba». Se trata de la reproducción de un equívoco legendario que deriva del nombre dado por Plinio al río Ter («río Alba»; Plin. NH 3.22). La idea de que Alba era la primigenia ciudad de Emporion puede remontarse, al menos, a la obra de Pere Beuter $(1546,33$ r) y tuvo un notable arraigo en el ámbito catalán y gerundense, en ocasiones adornada con material fantástico adicional (atribuyendo la fundación a Ascanio, hijo de Eneas, en recuerdo de la Alba itálica) y relacionando la raíz con otros gentilicios y topónimos del Empordá (Pujades 1609, 36v, e. g.). Si bien en la época de Montseny el mito ya había sido advertido y desechado insistentemente (Botet y Sisó 1879, 21, e. g.), no es de extrañar su pervivencia en el imaginario popular, sobre todo a nivel local.

Comete otro desliz cuando, en la descripción de su recorrido por el yacimiento, menciona el arco de la entrada de la ciudad, sorprendiéndose por el espesor de la muralla de «hormigón»; ella la identifica en todo momento como la puerta y la muralla de la Ampurias griega, considerándola una muestra de su esplendor, cuando, en realidad, se está refiriendo a las defensas de la ciudad romana. Asimismo, tras refugiarse de la lluvia en el vano dejado por la erosión entre los paramentos, informa de que el hueco había sido un pasadizo para facilitar la defensa. A nivel académico no había dudas: la correcta identificación del recinto romano fue publicada desde el principio (Puig i Cadafalch 1909, 184-194), como bien conocido era el sistema constructivo y el efecto del arrastre del agua en el relleno del muro que había dejado esa apariencia de galería (Puig i Cadafalch 1909, 190-191, figs. 44 y 45 ).

De aún más calado es la disquisición que ocupa la tercera parte del artículo (Montseny 1926, 109-110). Aquí va más allá en su atrevimiento historiográfico y especula acerca de las posibles explicaciones sobre el final de la ciudad, que, según presupone, debió ser súbito y catastrófico, y baraja distintas posibilidades, tanto desastres naturales (un terremoto o una tormenta de arena) como bélicos (un posible asalto desconocido). Es cauta, no apuesta por ninguna opción y advierte de la falta de pruebas para cualquiera de las teorías; prefiere jugar así, literariamente, con el gran enigma del fin repentino de una floreciente urbe helena en todo su esplendor. De nuevo, a nivel académico, estaba plenamente asentada la idea de que la ciudad antigua había vivido un proceso de decadencia progresiva (Botet y Sisó 1879, 128-135; Puig i Cadafalch 1909, 192-194, e. g.).

En efecto, si bien las excavaciones se acompañaron desde el inicio de una abundante publicación científica (Ripoll i Perelló 2001, 44-48), otra cosa distinta sería la información que circulaba en ambientes menos rigurosos. Se ha apuntado, por ejemplo, cómo la prensa catalana que publicitaba los hallazgos difundió erróneamente la atribución griega de la puerta y la muralla romanas (Munilla \& Gracia Alonso 2016, 387-388). Asimismo, cabe citar «Ressons d'Empori», el discurso de la poetisa Caterina Albert (con el pseudónimo de Víctor Catalá) para su ingreso en la Reial Acadèmia de Bones Lletres de Barcelona en 1922 (Bofarull 1993). En él sintetiza los hallazgos hechos 
en los últimos tiempos (los conocía bien como coleccionista que era) para rebasarlos con múltiples elucubraciones pseudohistoriográficas, probablemente motivadas por su fervor de ampurdanesa. Aparte de su obsesión por atrasar la cronología de los restos, desarrolla, precisamente, la teoría de la destrucción catastrófica: menciona que circulaba la hipótesis del terremoto, aunque ella la descarta, pues apuesta por un escenario de invasión extranjera en la que los habitantes cayeron de forma heroica (Català 1922, 172-175).

Dada la ligereza con la que Montseny maneja la información en el artículo, es probable que nunca llegase a documentarse con ninguna lectura específica, ni siquiera del tipo de la de Català. Da la impresión de que sus datos le llegaron de segunda mano, quizá por la prensa o por lo que le contaron aquellos amigos de L'Escala que la guiaron. Es obvio que su artículo no tiene como objetivo la divulgación historiográfica, aunque juegue con elementos históricos, pues su planteamiento es fundamentalmente reflexivo. Ahora bien, estos detalles son interesantes porque nos hablan de la manera en la que el conocimiento arqueológico e historiográfico sobre Ampurias se estaba filtrando a distintos niveles, y es obvio que esas inercias no eran inocuas ideológicamente.

\section{LA LUMINOSA SONRISA DE GRECIA}

«Pero yo, sobre las ruinas de la ciudad griega sepultada, no hubiera reunido en asamblea milenaria a todas las religiones (...), habría evocado yo a las sacerdotisas de Afrodita, a los dulces donceles alados del Eros griego. En la noche soñada, el pasado hubiera revivido la luminosa sonrisa de Grecia bajo este cielo único del Ampurdán. Y los pobladores de estas costas, que guardan en su porte, en su ruda majestad y en su vigor de pescadores algo del ritmo y la gracia griega, habrían aparecido ante mi mente como descendientes y últimos depositarios de la lejana Héllada.» (Montseny 1926, 108)

La Ampurias antigua de Montseny es la Ampurias griega, a ella se está refiriendo cuando habla de ruinas majestuosas y viajes en el tiempo, esa es su Antigüedad por antonomasia, mientras que lo fenicio es anecdótico y lo romano completamente ignorado. Además, su visión es absolutamente idílica, aunque ciertamente inconcreta; está representada por figuras mitológicas típicas con un sentido muy nebuloso, de manera que lo que transmite es una proyección muy esquemática, abstracta, que no necesita de explicaciones ni motivos concretos. Por otro lado, se trata de evocar una Grecia ideal, pero en aquel lugar en particular, lo que concierne también a ese marco natural característico: recalca que ese mar omnipresente no es cualquier mar, sino el Mediterráneo («el mar de Anfitrita», en alusión a la esposa de Poseidón), que aquel cielo y su luz especial no son otros que los del Empordá y que todo ese antiguo encanto se refleja, precisamente, en los pobladores de esas costas. El suyo es todo un alegato de exaltación del legado de Grecia en Catalunya, lo que, de nuevo, tiene pleno sentido en su contexto. No es casualidad que buena parte de esos equívocos historiográficos que le habían llegado tuviesen que ver con la errónea identificación como griegos de elementos que no lo eran. En su tiempo había una tendencia a ver a Grecia en todas partes, en una mezcla de magnificación poética, error inconsciente, empeño irracional o deliberada manipulación, según el caso, que formaba parte de un ambiente político muy específico.

Cuando Prat de la Riba promovió las excavaciones de Ampurias y estas se centraron en la ciudad griega, no se trataba solo de fomentar la cultura catalana, era también una manera de apuntalar una determinada versión de esta. Frente al catalanismo tradicional, enfocado en los supuestos antecedentes fundacionales medievales, la nueva propuesta apostaba por un rastreo de las raíces originarias, según el modelo autoctonista que triunfaba en Europa. Esto conllevaba remontar la ca- 
talanidad al horizonte de los pueblos ibéricos, cuya esencia étnica se habría mantenido a lo largo del tiempo a pesar de las conquistas; no obstante, un factor decisivo en la evolución de ese sustrato original sería la influencia de la civilización griega, el clímax de la cultura clásica, que habría arraigado de manera exclusiva en aquella región distinguiéndola del resto de la Península. Se formulaba así una identidad esencialista alternativa a la espańola, en la que se minimizaba el elemento romano, tradicionalmente asociado con la unidad y el centralismo imperialista español. Ese trinomio de raza ibérica - civilización griega - pueblo catalán, promovido por Prat de la Riba en obras tan influyentes como La nacionalitat catalana (1906), fue el que se impuso en el primer tercio del siglo xx, alzando a Ampurias como insignia (Gracia Alonso 2013; 2017). Así, el clasicismo literario novecentista, el impulso de la arqueología prerromana y el discurso político filohelenista actuaban como los tres pilares de un proceso de reinvención e intensificación identitaria.

No hay duda de que el artículo de Montseny participa de esa inercia omnipresente en el denso ambiente catalán del momento. Está en la formulación de esa esencia netamente mediterránea que entronca con el presente, y en su esquemática concepción de un helenismo luminoso, equilibrado, puro y bello sin fisuras. En este punto, cabe preguntarse ¡es el filohelenismo de Montseny un alegato catalanista?

Para evitar una lectura demasiado simple hay que tener en cuenta, en primer lugar, los límites de su helenismo, pues no puede ser visto como un discurso bien definido y acotado. Por ejemplo, en su exaltación de las distintas divinidades, Afrodita tiene una presencia recurrente, pero se nombra indistintamente su versión fenicia y romana ("Astarté» $\mathrm{y}$ «Venus»), de la misma forma que considera un símbolo central el «templo de Diana» (quizá inspirada por uno de los sonetos de Gorgot, con ese título). Al hilo de esto, un artículo de Montseny de esos años se titula "Las vestales del ideal», que, a pesar de su alusión a las sacerdotisas romanas, nada tiene que ver con la Antigüedad, sino que habla de las reuniones en casa de Teresa Claramunt de varias viejas militantes y esposas de anarquistas represaliados (Montseny 1930; vid. Montseny 1987, 44). Es decir, que más allá de su uso ligero de los elementos antiguos y sus deslices terminológicos, la cuestión es que no parece haber una voluntad clara de delimitación de lo griego dentro de esa nebulosa antigua, por mucho que la asocie automáticamente con lo heleno o ignore la fase romana de Ampurias. Su fascinación por lo antiguo y, en particular, por las sacerdotisas y el imaginario mitológico es algo básicamente simbólico, casi estético, que remite a una ideal e inconcreta libertad primitiva. Desde luego, en su artículo se deja llevar por esa aura idealizante que Grecia tenía en su momento, pero en ningún caso parece que se esté esforzando por apuntalar una identificación cerrada, ese no es su objetivo.

Para completar este razonamiento, cabe acercarse a su entorno ideológico más inmediato y hacer alguna consideración acerca de cuál era el posicionamiento anarquista en aquel proceso nacionalizador. Por un lado, desde un punto de vista teórico, el anarquismo tendió a considerar el problema catalán como un conflicto básicamente burgués, promovido por intereses capitalistas. Además, les separaba del nacionalismo la aversión al propio concepto de Estado y su general concepción internacionalista; más concretamente, la CNT y la FAI no podían sino reprochar al catalanismo conservador de la Lliga su colaboracionismo con el Gobierno central para reprimir los movimientos obreros, especialmente en el sangriento periodo entre 1916 y 1923 . Dicho esto, no puede aislarse una postura única del anarquismo hacia el catalanismo, pues sí compartía con sus versiones más progresistas, como la defendida por la posterior ERC, ciertas tesis en contra del centralismo español; así, si bien los pensadores ácratas tendieron a desmarcarse del proyecto político del independentismo, sus opiniones a menudo fueron ambiguas, lo que incluye a los Montseny y la línea editorial de La Revista Blanca (Corti 1972).

Otro artículo de esta revista es particularmente pertinente en la cuestión que nos ocupa. «Grecia en Cataluña», firmado por Juan Mas Cabré, considera tres elementos definitorios de lo griego que 
coinciden con la visión de Montseny: «serenidad de juicio, armonía de líneas, alegría de vida» (Mas Cabré 1923, 2), de forma que identifica el «alma griega» en el gusto catalán por el canto, la danza y la sencillez artística. Imagina, por otro lado, un hipotético enfrentamiento entre fenicios y griegos en el pasado, pero básicamente como un juego con el que simbolizar una pugna presente: la lucha entre el espíritu del poeta, animado por la virtud espiritual (lo griego), y el espíritu del mercader, movido por intereses materiales egoístas (lo fenicio). Según él, estaba triunfando el segundo: se había establecido un gobierno catalán de mercaderes (léase, burgueses), apoyado por un ejército castellano (léase represión y terrorismo de Estado), de forma que dicha confabulación mantenía el flujo de riqueza a costa del trabajador atacado, desorganizado y empobrecido. Según él, el espíritu griego pervivía en los obreros que luchaban, pero que también cantaban y celebraban, así como en los artistas que tenían que cultivar su talento en el extranjero; en ellos residía el futuro idealista, justo y libre, del pueblo catalán.

Es muy interesante cómo se retuerce el sentido de los mismos tópicos esencialistas. Mas Cabré está arremetiendo contra la burguesía catalanista apropiándose, precisamente, de su baluarte identitario, el helenismo, al identificar en sus acciones las actitudes de su opuesto histórico, los fenicios. Al mismo tiempo, se arroga el legado griego para la causa obrera; eran los que luchaban por ella los verdaderos detentadores de aquella esencia: los obreros alegres y los artistas exiliados. Tanto en Mas Cabré como en Montseny, esa invocación estereotipada e irracional de lo griego quedaba supeditada al principio de la justicia social que motivaba el discurso. De hecho, su uso es fundamentalmente metafórico, pues en estos escritos la identidad greco-catalana no conlleva ni legitima nada en sí misma, al modo nacionalista, sino que es la causa filosófica y política la que importa, mientras que el referente histórico es poco más que un recurso literario para expresarla.

\section{LA COLUMNA Y LA TUMBA}

«Pero de Ampurias, de las ruinas de sus tres civilizaciones, puede también sacarse una consecuencia, encontrarse en ella un símbolo.» (Montseny 1926, 110)

Puede que haya en el texto de Montseny una idealización romántica del pasado y una tendencia filohelenista característicamente catalana, pero, al fin y al cabo, se trata de una anarquista escribiendo en una revista anarquista, y su mensaje principal va por otro lado. Su visión de lo griego no responde tanto a la singularización de lo catalán como a la contraposición ideológica de dos referentes del pasado, ya no ampuritano ni catalán ni español, sino universal.

A lo largo de todo el texto, la autora va lanzando una serie de visiones, unas más abstractas y otras muy concretas, pero que se alinean nítidamente en dos vertientes opuestas, un juego de paralelismos que, finalmente, resuelve en la cuarta y última parte del artículo (Montseny 1926, 110). Es donde hace explícito lo que las ruinas le han sugerido, a modo de solución de lo que había sido un complejo puzle de imágenes oníricas.

Ya en aquella segunda parte más descriptiva había apuntado la presencia de testimonios medievales junto a la ciudad griega, esto es, los escasos restos del Castillo de Sant Martí d'Empúries (siglos XIII-XIV), el Convento de Nostra Senyora de Gràcia (siglo XVII) (sede del museo desde 1914) y las ruinas de su iglesia. El castillo, el convento y la iglesia, que define como «tres símbolos» $\mathrm{y}$, añade, estaban rodeados por las «casuchas de los vasallos» construidas con piedras de la ciudad antigua. No hace más matices ni desarrolla ninguna explicación, pero el sesgo es obvio al esbozar, con la simple presentación de esos restos materiales, una realidad marcada por la desigualdad. 
Pero va más allá, con una reflexión básicamente estética y filosófica. Esas ruinas, unas y otras, en su calidad de lugar de memoria históricamente cargado, sirven como puntos de anclaje para hablar en el último punto de dos concepciones, la brillantez poética que le sugiere Grecia frente a la oscuridad del contrapunto medieval. En particular, dos elementos sirven para condensar físicamente esa dualidad: por un lado, las columnas "gráciles» y «esbeltas» de los templos antiguos; por otra, las tumbas junto a la iglesia. Si estas son el recuerdo «lúgubre» de la ritualidad cristiana, contrastan con «el más sereno, estético y sabio» de la cremación helena. Al final, todo ello puede resumirse en una sencilla contraposición genérica entre la vida y la muerte: «De su templo de Diana, con sus columnas graciosas mirando al mar, y de su iglesia medieval con muertos dificultando el paso de los vivos, puede sacarse la conclusión de dos conceptos sobre la vida, eterno el uno porque revive en la eternidad humana; finito el otro porque solo de la muerte se alimenta» (Montseny 1926, 110). Culmina el artículo preguntándose qué concepción debe prevalecer, si la que está regida por la muerte de un hombre veinte siglos atrás o la que piensa en el futuro de la humanidad que renace, representando esa disyuntiva mediante una idea metafórica: una cuna que se mece sobre las tumbas.

Así, la idea fundamental que Montseny extrae de su paseo entre ruinas es la oposición frontal entre un concepto del mundo fundamentado en la vida y la belleza, y otro basado en el dolor y la muerte. En este sentido, creo que la práctica ausencia de la fase romana no se debe solo a su desplazamiento como referente en el imaginario catalán — que también-, sino que constituye una omisión útil para establecer esa dicotomía de forma clara, sin transición. De hecho, entre el punto segundo —en el que describe el sitio_ - y el cuarto —en el que desarrolla su reflexión_-, está la parte en la que elucubra sobre el final catastrófico de la ciudad antigua, de modo que establece una secuencia ficticia, pero muy sugestiva, entre el esplendor griego, su final abrupto y la nueva fase de oscurantismo medieval. Es curioso lo que dice el prólogo que Josep Carner hizo a ese libro de poemas de Gorgot que quizá inspiró a Montseny: «el passat clássic i medieval que es mostra a flor de terra com un somriure de promissió donant testimoni d'una substáncia ideal immanent, irrenunciable, inextingible» (Carner 1918, 15). Ese dualismo era patente en las ruinas de Ampurias, pero si Carner y el catalanismo en general lo entendían como una dicotomía fundacional, Montseny lo vio como un antagonismo irreconciliable.

Está claro que, para ella, la cultura griega era símbolo de libertad y filosofía vital, pero no formula realmente una exaltación del paganismo antiguo ni hay una reflexión seria sobre la naturaleza de las religiones, pues los elementos religiosos con los que juega están siempre desprovistos de contenido concreto. Años antes, su padre sí escribió una breve disquisición sobre el tema como parte de una serie de artículos sobre la historia de la filosofía; reconociendo la existencia de cierta religiosidad natural, sin embargo, asociaba cualquier religión con tiranía, incluyendo el paganismo antiguo (Urales 1900). Antes que él, Proudhon ya había reflexionado sobre las continuidades entre paganismo y cristianismo a propósito de la Eneida (García Jurado 2014). Antes incluso, Volney, representante de la Ilustración radical, había meditado sobre las mismas cuestiones en aquel libro sobre las ruinas de Palmira que distribuían desde La Revista Blanca (vid. supra). En todo caso, insisto, Montseny no está yendo tan lejos: ni analiza ni alaba ni critica el paganismo, pues, en su artículo, la ciudad antigua y su religión son simple ambientación idílica, casi puramente estética, utilizada, básicamente, para atacar al cristianismo.

Desde luego, podría decirse que hay un cierto gusto anticlerical en el texto, pero lo cierto es que tampoco pone el foco en las dimensiones sociales, políticas ni económicas de la religión, ya que solo alude a este aspecto tangencialmente. En cambio, su planteamiento es más abstracto, de corte filosófico. No es casual que entre los dioses antiguos que representan su visión idílica estén 
especialmente presentes Afrodita y Eros; en esta línea, el término que más se repite en ese juego de contraposiciones es «vida». Aparentemente, todo ello entronca con ciertas postulaciones suyas sobre la moral, el amor, la pasión y la familia que ocuparon un lugar central en su obra literaria y ensayística (Cruz-Cámara 2015). Sobre este tema, simplificando, Montseny cultivó intensamente cierta línea de pensamiento dentro del anarquismo que ponía su énfasis en la consagración personal y militante a la mejora de la existencia, individual y colectiva, esto es, a la tarea esencial de crear vida y mejorar la de los demás. La condición inexcusable para que eso fuese posible con todo su potencial era desarrollar un proceso por el cual se desechasen sistemáticamente todas las limitaciones (mentales y sociales) derivadas de la asunción de cualquier tipo de dogma o prejuicio moral. Por supuesto, esto último se concebía como un ataque a las constricciones cristianas, pero también conllevaba la defensa de ciertas nociones (como el amor o la pasión irracional) que estaban siendo desnaturalizadas desde algunos planteamientos de la izquierda radicalmente materialista. Ese es el tipo de vida que Montseny atribuye a lo griego, la sonrisa luminosa de Grecia frente a la oscuridad medieval.

Estudiar los referentes del pasado en el anarquismo es interesante, entre otras cosas, porque hay en él una voluntad consciente y explícita, incluso obsesiva, de desligarse de la tradición, ya sea intelectual, identitaria o religiosa, una necesidad imperiosa de que cada cuestión planteada sirva para cuestionar algún fundamento hegemónicamente aceptado. Esta motivación teórica hace especialmente estimulante profundizar en la manera en que estos pensadores articularon sus ofensivas a los esquemas preconcebidos con sus propias inercias y contradicciones.

El artículo de Montseny es un trabajo sencillo y sin pretensiones, una reflexión escrita a vuelapluma sobre una pequeña experiencia personal. No obstante, en sus distintos elementos pueden intuirse indicios que nos hablan de ciertos procesos de conceptualización del pasado. Hay un nivel esencialmente poético en su aproximación onírica y cautivada a la Antigüedad, a la que da forma mediante el recurso a los tópicos literarios más convencionales. Se muestra, además, un componente identitario básicamente inconsciente, interiorizado, fruto de un ambiente de esencialismos exacerbados, cuando perfila esa identidad griega idílica y la entronca irracionalmente con su realidad presente. Si la información historiográfica y arqueológica con que se concreta está repleta de equívocos y mitos es porque, en realidad, importa poco. Lo fundamental es el símbolo, de manera que los restos materiales, en su calidad de lugar de memoria, quedan esquematizados y desprovistos de matices para representar una dicotomía fundamental, que no tiene nada que ver con identidades concretas, sino con concepciones filosóficas universales. Es en ese punto donde reside el mensaje deliberado, la motivación consciente del texto, la rabia y la pasión de quien solo concibe los restos del pasado como un pretexto para hablar de luchas futuras.

\section{BibLIOGRAFÍA}

AlCALde, C., 1983, Federica Montseny: palabra en rojo y negro, Barcelona: Argos Vergara.

Aquilué Abadías, X. (ed.), 2001, Josep Puig i Cadafalch, Empúries i l'Escala, L'Escala: Ajuntament de l'Escala-Museu d'Arqueologia de Catalunya.

Beuter, P. A., 1546, Primera parte de la Coronica general de toda España y especialmente del reyno de Valencia, Valencia: Joan de Mey Flandro.

Bofarull, B., 1993, "Victor Català i Empúries», en: E. Prat i Pep Vila (ed.), Actes de les Primeres Jornades d'Estudi sobre la Vida i l'Obra de Caterina Albert i Paradis "Victor Català», Barcelona: Publicacions d'Abadia de Montserrat. 
Borx Llonch, L., 2001, «El ressò de les excavacions d'Empúries a l'Escala», en: Aquilué Abadías 2001, 56-71.

Botet y Sisó, J., 1879, Noticia historica y arqueologica de la antigua ciudad de Emporion, Madrid: Alejandro Gómez Fuentenebro.

CABré, R. et al., 2003, Polis i nació: politica i literatura (1900-1939), Barcelona: Societat Catalana d'Estudis Clàssics.

Carner, J., 1918, «Pròleg», en A. Bruguière de Gorgot, Dans les ruines d'Ampurias, Paris: Sengarad.

Català, V. (Caterina Albert), 1922, "Ressons d'Empori», Butlletí de la Reial Acadèmia de Bones Lletres de Barcelona 10/76, 345-379.

Cortadella Morral, J., 2009, «L'Empúries imaginada: músics, erudits i lletraferits», Faventia 31/1-2, 253-262.

Corti, A., 1972, “La Revista Blanca» i el problema català», Recerques 2, 191-208.

Cruz-Cámara, N., 2015, La mujer moderna en los escritos de Federica Montseny, Woodbridge-Rochester: Tamesis.

FERrI, E., 2017, «Cultura clásica y pensamiento libertario», Tierra y Libertad 352.

Ferri Coll, J. M., 1995, Las ciudades cantadas: el tema de las ruinas en la poesía española del Siglo de Oro, Alicante: Universidad de Alicante.

García Cardiel, J., 2013, «Numancia y Sagunto en el imaginario español (1582-1937). Una lectura histórica a través de la literatura», Revista de Historiografía 18, 41-51.

García Jurado, F., 2014, «La Eneida como utopía regeneradora: Pierre-Joseph Proudhon», Studia Philologica Valentina 16, 51-68.

García Morales, F., 2012, «Heracles y el león de Nemea. Huellas de la cultura clásica en la simbología anarcosindicalista», Estudios: Revista de Pensamiento Libertario 2, 102-116.

Gracia Alonso, F., 2013, "Archaeology and Nationalism: The Development of Archaeology in Catalonia in the Early Twentieth Century», Complutum 24/2, 131-144.

Gracia Alonso, F., 2017, «The Invention of Numantia and Emporion: Archaeology and Regeneration of Spanish and Catalan Nationalisms after the Crisis of 1898», en: A. de Francesco (ed.), In search of preclassical Antiquity: rediscovering ancient peoples in Mediterranean Europe (19th and 20th c.), Leiden-Boston: Brill, 64-95.

Hofmann, B. et al. (eds.), 1995, El anarquismo español y sus tradiciones culturales, Frankfurt: Vervuert.

Lida, C. E., \& P. Yankelevich (eds.), 2012, Cultura y politica del anarquismo en España e Iberoamérica, México D. F.: El Colegio de México.

LitvaK, L., 1995, «La prensa anarquista (1880-1913)», en: Hofmann 1995, 215-236.

Lozano, I., 2004, Federica Montseny: una anarquista en el poder, Pozuelo de Alarcón: Espasa.

Madrid SANTOS, F., 1989, La prensa anarquista y anarcosindicalista en España desde la I Internacional hasta el final de la Guerra Civil, Barcelona: Universitat de Barcelona.

Marín i Silvestre, D., \& S. Palomar i Abadía, 2010, Els Montseny Mañé: un laboratori de les idees, Reus: Carrutxa.

Mas Cabré, J., 1923, «Grecia en Cataluña», La Revista Blanca, Año I (Segunda Época) 5 (01/08/1923), 2-4.

Montseny, F., 1926, «La ciudad muerta. Ruinas de Ampurias», La Revista Blanca, Año IV (Segunda Época) 76 (15/07/1926), 108-110.

Montseny, F., 1930, «Las vestales del ideal», La Revista Blanca, Año VII (Segunda Época) 7 (01/02/1930), 397-399.

Montseny, F., 1987, Mis primeros cuarenta años, Esplugues de Llobregat: Plaza \& Janés.

Moormann, E. M., 2015, Pompeii's Ashes: The Reception of the Cities Buried by Vesuvius in Literature, Music, and Drama, Boston-Berlin-Munich: De Gruyter.

Morales Muñoz, M., 2002, Cultura e ideología en el anarquismo español (1870-1910), Málaga: CEDMA.

Munilla, G., \& F. Gracia Alonso, 2016, «Ampurias y los orígenes del turismo arqueológico en Cataluña», Boletín del Museo Arqueológico Nacional 34, 383-404. 
Nettlau, M., 1929, «De la caída de la antigua Roma a la transformación del porvenir I», La Revista Blanca, Año VII (Segunda Época) 152 (15/09/1929, 177-182).

Puig i Cadafalch, J., 1909, "Les excavacions d'Empúries. Estudi de la topografía», Anuari de l'Institut d'Estudis Catalans 2, 152-193.

Puig i Cadafalch, J., 1936, «Les excavacions d'Empúries», Anuari de l'Institut d'Estudis Catalans 8, 56-59.

Pujades, J., 1609, Coronica universal del principat de Cathalunya, Barcelona: Hieronym Margarit.

Ripoll i Perelló, E., 2001, "Josep Puig i Cadafalch, arqueòleg», Butlletí de la Reial Acadèmia Catalana de Belles Arts de Sant Jordi 15, 29-54.

Rodrigo, A., 2014, Federica Montseny: primera ministra electa de Europa, Barcelona: Base.

Serra i Ràfols, J. C., 1931, "Les excavacions d'Empúries», Anuari de l'Institut d'Estudis Catalans 7, 81-84.

Termes Ardèvol, J., 2011, Historia del anarquismo en España (1870-1980), Barcelona: RBA.

Trullén i Thomàs, J. M., \& C. Martinell i Callico, eds., Fascinació per Grècia: l'art a Catalunya als segles XIX $i$ XX. Girona-Barcelona: Museu d'art de Girona-Generalitat de Catalunya, Departament de Cultura i Mitjana de Comunicació, 2009.

Urales, F. (Joan Montseny), 1900, «La evolución de la filosofía en España (continuación del primer capítulo)», La Revista Blanca, Año III 51 (01/09/1900), 65-68.

Vadillo Muñoz, J., 2019, Historia de la CNT: utopía, pragmatismo y revolución, Madrid: Los Libros de la Catarata.

Vallcorba Plana, J., 1994, Noucentisme, mediterraneisme i classicisme: apunts per a la história d'una estètica, Barcelona: Quaderns Crema.

Valle-Inclán, J. del, 2008, Biografía de La revista blanca: 1898-1905, Barcelona: Sintra.

Vallvé Albiol, I., 2005, "Manuel Cazurro Ruiz, pioner d'Empúries i col.leccionista», Annals de l'Institut d'Estudis Gironins 46, 367-405.

Velaz i Sicart, A. M., 2003, “'Dans les ruines d'Ampurias”, d'Andrée Bruguière de Gorgot: una aportació en llengua francesa a la proposta cultural noucentista», en: M. C. Zimmermann, A. Charlon (eds.), Actes del dotze Colloqui Internacional de Llengua i Literatura Catalanes, Barcelona: Publicacions de l'Abadia de Montserrat, vol. 2, 203-219. 